\title{
Rescue lithotripsy to treat basket impaction
}

The complications of mechanical lithotripsy include a trapped basket surrounding the stone, fracture of the basket wires or the main operation wire, malfunction of the mechanical lithotriptor crank handle, and ductal injury $[1,2]$. Impaction of a basket with a captured stone inside occurs occasionally not only during mechanical lithotripsy but also during removal of small stones with non-lithotriptor basket catheters. Clinically, impaction of a basket with a small stone can occur because of stenosis of the distal biliary tract. Basket impaction is a severe complication, which usually needs an additional procedure. We here describe and illustrate the use of rescue lithotripsy to treat this complication.

When unexpected impaction of a basket occurs during endoscopic retrograde cholangiopancreatography (ERCP; @ Fig. 1), the basket catheter must be cut close to the catheter handle. The endoscope and outer sheath of the basket catheter must then be removed ( $\bullet$ Fig. 2 ). A snare catheter without the outer sheath is passed through a previously shortened metal sheath used for mechanical lithotripsy. The appropriate length for the metal sheath is determined by the length of the traction wire for the basket catheter. This method is useful because the tip of the traction wire, which would be difficult to pass through the commonly used metal sheath, is made up of several wire bundles that easily come untied. A bundle of the traction wire is untied at the cut end and several wires are folded back through the tip of the snare. The snare catheter is then slowly pulled back through the metal sheath drawing the traction wire with it and out of the metal sheath ( $\bullet$ Fig.3). The metal sheath is then passed through the alimentary tract over the traction wire ( $\bullet$ Fig.4). This allows the traction wire to be more tightly fixed $(\bullet$ Fig. 5 and $\bullet$ Fig. 6 ) and the calculi can then be crushed. If the traction wire fractures at the outer end of the wire, the above procedure can be repeated using a shorter metal sheath [2].

\section{Endoscopy_UCTN_Code_TTT_1AR_2AK}

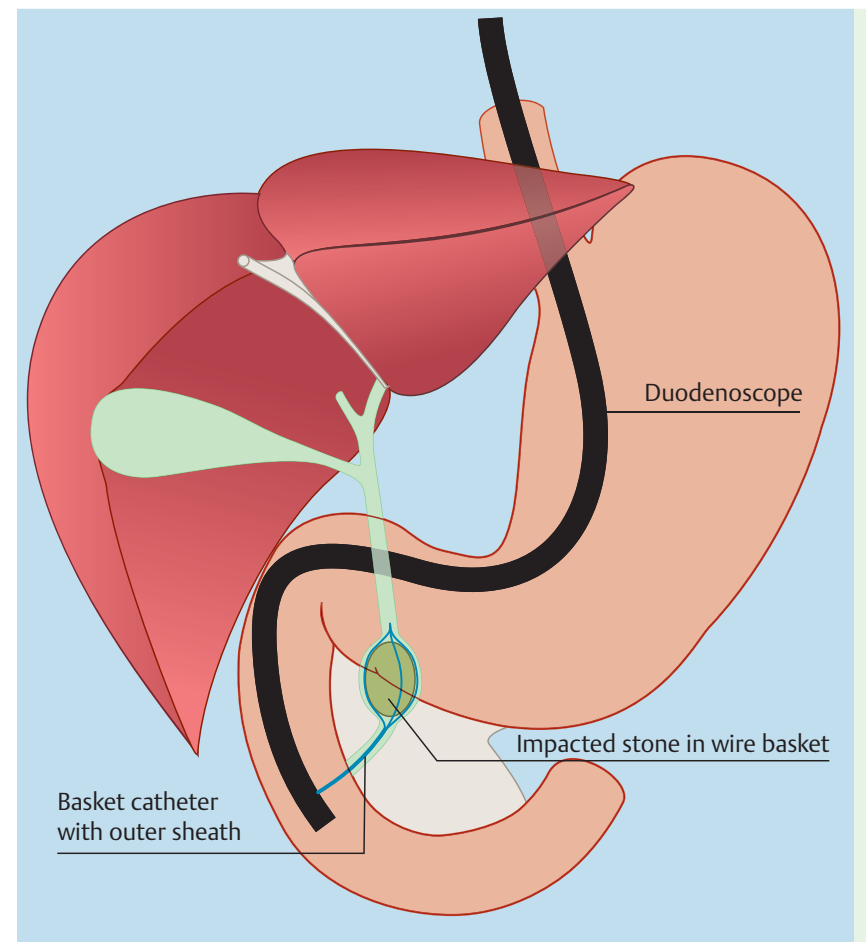

Fig. 1 Schematic of an impacted basket containing a captured stone. This occurs occasionally during removal of a stone with a non-lithotriptor basket catheter.

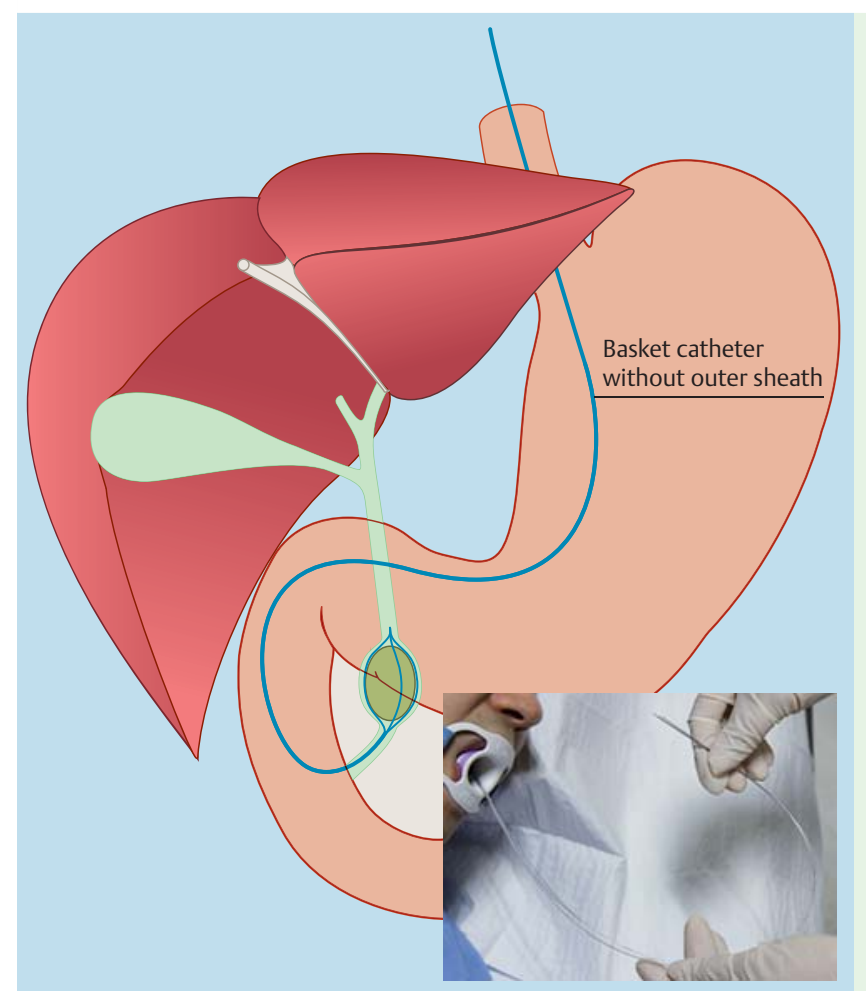

Fig. 2 After the basket catheter has been cut close to the catheter handle, the endoscope and outer sheath of the basket catheter are removed. Inset The cut end of the basket catheter is left protruding through the mouth of the patient.

\section{Competing interests: None}



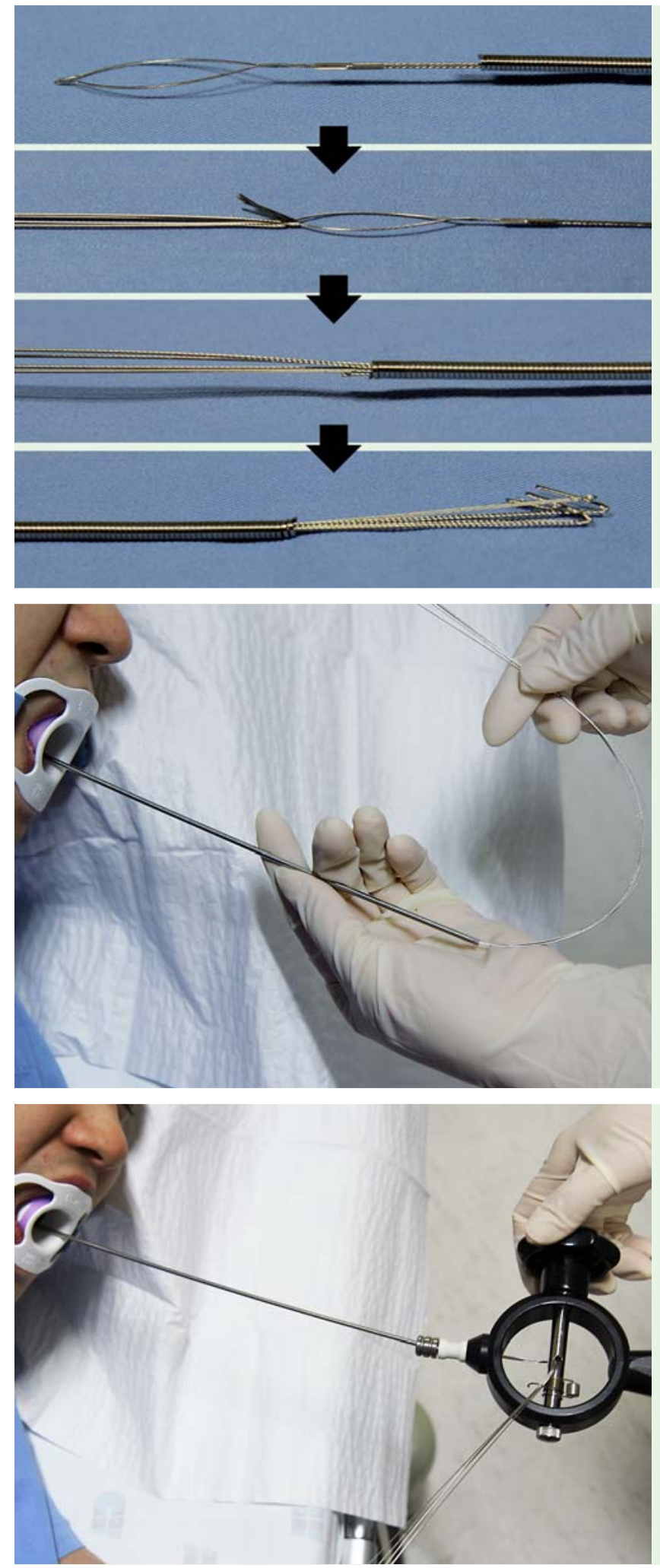

Fig. 3 Sequential images illustrating the traction wire being passed through the metal sheath. This procedure is easily performed once the outer sheath has been removed from the snare catheter.

Fig. 4 The metal sheath is passed through the alimentary tract over the traction wire.

Fig. 5 The traction wire is tightly fixed using a lithotriptor handle and rescue lithotripsy is then performed to crush the calculi.

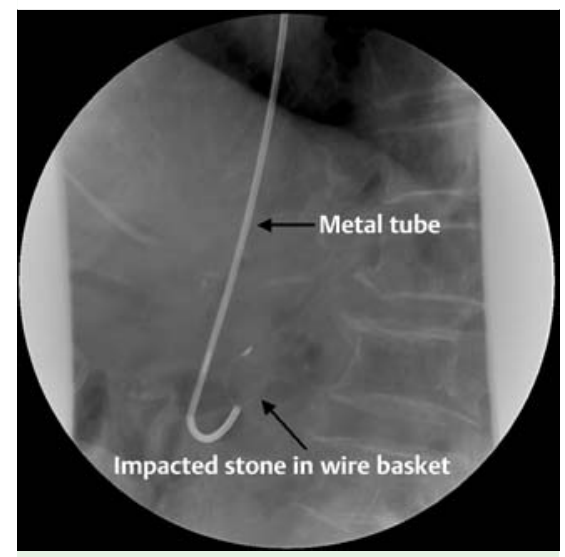

Fig. 6 Radiographic image showing the final step in the rescue lithotripsy. The outer sheath of the basket catheter is replaced with the metal sheath through which the traction wire is then tightly fixed.

\section{W. H. Kim', C. I. Kwon', J. H. Han ${ }^{2}$}

${ }^{1}$ Digestive Disease Center, CHA Bundang Medical Center, CHA University,

Seongnam, South Korea

2 Division of Gastroenterology, Department of Internal Medicine, Chungbuk National University College of Medicine, Cheongju, South Korea

\section{References}

1 Thomas M, Howell DA, Carr-Locke D et al. Mechanical lithotripsy of pancreatic and biliary stones: complications and available treatment options collected from expert centers. Am J Gastroenterol 2007; 102: 1896-1902

2 Hintze RE, Adler A, Veltzke $W$ et al. Management of traction wire fracture complicating mechanical lithotripsy. Endoscopy 1997; 29: $883-885$

\section{Bibliography}

DOI http://dx.doi.org/

10.1055/s-0032-1308944

Endoscopy 2012; 44: E209-E210

(c) Georg Thieme Verlag KG

Stuttgart · New York

ISSN 0013-726X

\section{Corresponding author}

\section{C.-I. Kwon, MD}

Digestive Disease Center

CHA Bundang Medical Center, CHA University

351 Yatap-dong, Bundang-gu

Seongnam, 463-712

South Korea

Fax: +82-31-7805219

endoscopy@cha.ac.kr 